\section{Damned if they do}

An industry approach to greener hydropower is far from perfect, but it does offer a way forwards.

$\mathrm{T}$ he mighty Iguaçu Falls in Brazil are an excellent illustration of the power of water, so what better place for the hydropower industry to promote what it says is a fresh approach to its sustainability?

There is ample room for scepticism about the effort - known as the Hydropower Sustainability Assessment Protocol (see page 430). It is an industry-led endeavour that requires next to nothing from the industry. It grades hydropower projects, but makes no judgement on what should happen to projects that rank poorly. And it is geared towards assessment of individual dams, independent of broader questions about energy-resource development. So far, so bad. Yet, if deployed properly, it could also be an invaluable tool to inject muchneeded science and reason into a planning process that has operated with little of either for much too long.

Developers and governments have historically assessed dam projects mainly on the basis of cost and power. Engineers simply survey the landscape to identify the easiest places to block channels, set up turbines and run power lines. Sediments, endemic species and the consequences of severing communication between headwaters and estuaries are very much secondary issues. Even people get short shrift, leading indigenous groups to mount the kind of intense protests that last week saw the Peruvian government shelve plans for a massive dam in the Amazon.

This standard approach has caused numerous environmental problems - such as siltation and blockages to migrating fish - in industrialized countries, which exploited their best hydropower resources long ago and are now trying to repair the damage. In some cases, the costs of improvement outweigh the benefits, and old dams are being decommissioned. But, in the developing world, hydropower projects continue to stack up. Countries in Southeast Asia and Latin America, in particular, are pursing hydropower with gusto, hoping to alleviate energy poverty and feed burgeoning economies. By one optimistic industry estimate, cumulative hydropower capacity could nearly double by 2030 . Without a more coordinated approach, these countries are doomed to make the same mistakes.

The new hydropower protocol comes courtesy of the International Hydropower Association, which consulted with environmental and human-rights groups, as well as representatives from finance and government, in an effort to set out some basic principles of sustainable hydropower.

After three years of work, the result is a way to assess dam projects on a range of criteria - from planning, governance and public engagement to ecology and hydrology. It is voluntary, however, and there are no minimum standards. The protocol asks all the right questions but fails to provide any answers.

This has driven a wedge into the community of environmental and social activists that work in this arena. Critics argue that the protocol represents little more than a public-relations exercise that will allow bad developers to appear green while pursuing business as normal often on projects that pre-date current environmental thinking. This

"The hydropower
assessment
protocolasks
all the right
questions but
fails to provide
any answers."
may be true, but, unfortunately, in the political and corporate world such 'greenwash' is common. The new effort would at least create a common language with which to raise concerns, evaluate the best available science and negotiate improvements.

The biggest shortcoming lies in the assessment of individual dams that have already been proposed for specific locations. Much better would be an approach to analyse entire river basins in an effort to identify the most suitable locations, as well as areas where special precautions should be taken. Indeed, it might well be that some rivers should be left to flow freely to preserve ecological integrity.

The protocol does touch on these issues, raising questions about a dam's role in the broader energy mix and about wider impacts from hydroelectric development. And it could yet offer a foundation to set minimum standards in these and other areas, so that companies would need to build and operate better dams, as well as integrate them into a more comprehensive energy strategy. For all of its faults, the protocol opens another bridge to a better future. Now it's up to governments, banks and companies to make the journey across.

\section{Poetry in motion}

\section{A quantitative approach to the humanities enriches research.}

$\mathrm{T}$ he Oscar-winning 1989 film Dead Poets Society is an unabashedly exuberant story that appeals to the Lord Byron in each of us. Robin Williams plays a charismatic English teacher at a conservative US prep school in the 1950s and, in one scene, gets his impressionable students to read a lesson from a poetry textbook aloud. The worth of a poem, they read, should be measured on two axes: its artistic perfection and its importance. As the schoolboys start to map out graphs in their notebooks, Williams cuts them off. "Excrement," he announces - that's what he thinks of the mathematical approach. A poem must be felt, not figured. He orders the boys to tear the page out of the textbook. "We're not laying pipe," he says. "We're talking about poetry."

It is hard to disagree with the spirit of that moment. We should all be passionate about our academic interests, and daring enough to rip up hidebound rules that govern them. But the scene's explicit disdain for quantitative analysis of text is as out of date as it is wrong. These days, it is the humanities scholars who equip themselves with quantitative skills who are most able to sound their 'barbaric yawps' over the roofs of the world, as Williams urged his students to do.

As the News Feature on page 436 shows, the field of digital humanities is flourishing, led by scientists such as those behind the innovative Google $n$-grams viewer, which can be used to track the frequencies of words and phrases as they appear in $4 \%$ of the books ever published. Whether mapping the transmission of Voltaire's letters across Europe, finding structural patterns in music across cultures or tracking the evolution of irregular verbs through time, these digital humanists have plenty to say. And they have the data to back it up.

That is not to say that traditional approaches in the humanities will be disappearing any time soon, or that careful, interpretive readings by experienced scholars are as arbitrary as the learning-by-feeling espoused by Dead Poets Society. But digitization is marching on, and in all subjects, researchers who have their ears to the ground, rather than their heads in the sand, can hear the approaching drums. Every day, more and more of the media that make up both historical and contemporary culture are being converted to electronica.

It seems just a matter of time before the humanities, like the social $\rightarrow$ NATURE.COM To comment online, click on Editorials at: go.nature.com/xhunqv sciences before them, wholeheartedly embrace scientific methodology. And that should be reason to rejoice, not remonstrate. As Williams implored his young charges: carpe diem. Seize the day.. 